\title{
"Eu quero muito trabalhar um tema": estratégias argumentativas no programa televisivo Conexões Urbanas
}

\author{
"I really want to work on a topic": argumentative strategies in a \\ Brazilian TV program
}

\section{Anna Christina Bentes}

Rafaela Defendi Mariano

\section{Ana Cecília Almeida Accetturi}

Universidade Estadual de Campinas - UNICAMP - São Paulo - Brasil

\begin{abstract}
Resumo: Neste artigo, buscamos analisar a natureza argumentativa do programa de reportagens televisivo Conexões Urbanas, exibido pelo canal fechado Multishow de 2008 a 2015, procurando investigar (i) a correlação entre os tipos de atores sociais que são convidados a participar do programa e os tipos de argumentos mobilizados por eles em suas falas e (ii) o papel das temáticas do programa na configuração do tipo de acordo estabelecido para a configuração do auditório. Nossas análises apontam para o fato de que ocorre uma predominância de certos tipos de argumentos na fala de certos tipos de atores sociais, o que revela que a estruturação argumentativa do programa é correlacionável ao status social de seus participantes. Por fim, verificamos que as temáticas e as estratégias argumentativas dos/nos episódios analisados configuram para cada um deles um perfil específico de auditório.
\end{abstract}

Palavras-chave: Argumentação. Reportagem televisiva. Gêneros televisivos. Atores sociais. Tipos de argumentos.

Abstract: In this article, we intend to analyze argumentative processes in a Brazilian TV program called Conexões Urbanas, recovered by the cable TV channel Mutishow between 2008 and 2015. We investigated the correlation between the types of social actors interviewed and the types of arguments present in their speech during the program. We also analyzed the role of the program's topics in the configuration of the audience. The analysis shows that there is a predominance of certain types of arguments in the speech of certain types of social actors. In other words, the program's argumentative structure can be correlated to the social status of the participants. Finally, we observed that the topics and the argumentative strategies analyzed configure different audiences for each one of the episodes.

Keywords: Argumentation. Brazilian Television Genres. Social Actors. Types of arguments. 


\section{Introdução}

Neste artigo, levando em consideração os resultados anteriores das análises do programa televisivo Conexões Urbanas ${ }^{1}$ nas quais foram empreendidos levantamentos das principais temáticas desenvolvidas $^{2}$ e dos atores sociais entrevistados, buscamos analisar a natureza argumentativa desse programa jornalístico que, a nosso ver, está intimamente relacionada tanto às temáticas estabelecidas como aos atores sociais chamados a participar do programa.

Partimos da observação de que, como cada episódio do programa possui uma tese enunciada pelo apresentador e/ou pelos entrevistados, ele é, assim, orientado, organizado e editado para a defesa dessa tese. Nossa hipótese é a de que a argumentação no Conexões Urbanas estrutura-se por uma correlação entre os tipos de atores sociais que são convidados a participar do programa e os tipos de argumentos (PERELMAN \& OLBRECHTS-TYTECA, [1996] 2005) mobilizados por eles em suas falas.

Procuramos investigar (i) a correlação entre os tipos de atores sociais que são convidados a participar do programa e os tipos de argumentos mobilizados por eles em suas falas e (ii) o papel das temáticas do programa na configuração do tipo de acordo estabelecido para a configuração do auditório.

É importante ressaltar que pretendemos explorar a argumentação no interior do Conexões Urbanas exatamente em função do fato de esse programa jornalístico configurar-se, a cada episódio, como uma reportagem que enfoca uma determinada temática de forma mais aprofundada, apresentando,

\footnotetext{
1 O programa Conexões Urbanas é apresentado por José Junior (JJ), coordenador-executivo do Grupo Cultural AfroReggae, e pretende ser visto como um tipo de "TV ação" ou ainda "TV mobilização" (BENTES, 2010) que busca mostrar as "transformações sociais bem-sucedidas no Brasil e no mundo" (SALLES; FAUSTINI, 2008). Esse programa faz parte do corpus do projeto "Estabilização e inovação dos gêneros midiáticos: tópico discursivo e categorização social" (Processo CNPq $309845 / 2013-0)$, cujo objetivo é o de analisar as dinâmicas de estabilização, adaptação e inovação de gêneros midiáticos televisivos da grande mídia.

2 Referimo-nos aqui aos trabalhos de Accetturi (2015a; 2015b) e Bentes et al. (2015).
}

muitas vezes, "um caráter denunciante" (KOTSCHO, 2000, p.71).

Trabalhos sobre mídia e argumentação vêm sendo desenvolvidos no campo dos estudos textuais. Porém, nesse campo observamos a predominância de investigações que se voltam para análises de textos escritos, como as empreendidas por Koch ([1987] 2011), Aquino e Lotti (2016), Aquino (2010), Cavalcante e Matos (2016) e Cabral (2016); ou para análises de gêneros discursivos considerados prototipicamente argumentativos (debates e entrevistas, por exemplo), como é o caso dos trabalhos de Aquino (1997), Palumbo (2007; 2013), Carvalho (2007); Farneda (2007), Lima (2009).

Como o objetivo geral deste trabalho é analisar os processos de argumentação que estruturam um gênero televisivo não prototipicamente argumentativo, consideramos que nossa maior contribuição pode ser a de mostrar como os atores sociais que dele participam estão relacionados aos tipos de argumentos mobilizados por esses atores e como as temáticas de cada episódio estão relacionadas aos tipos de audiência pressupostos pelo programa.

Para tanto, selecionamos dois episódios do Conexões Urbanas: Circo Social, da segunda temporada (2009), e Anistia, da terceira temporada (2010). Ambos merecem destaque, pois, segundo nossos levantamentos anteriores, esses episódios mobilizam as duas temáticas mais recorrentes no programa - "Projetos sociais/ONGs" e "Questões Sociais", respectivamente - conforme veremos na próxima seção, e apresentam uma maior diversidade de tipos de atores sociais entrevistados.

É importante considerar que os dois episódios analisados defendem teses específicas. No caso do episódio Circo Social, a tese é a de que o circo funciona como um vetor de transformação social da vida de seus artistas. No caso do episódio Anistia, a tese é a de que há necessidade de uma lei de anistia no país para os criminosos que demandam uma segunda chance para uma vida fora do crime. 


\section{Contextualizando o programa Conexões} Urbanas

\subsection{Configuração temática do programa}

Para analisar as contribuições dos diferentes tipos de atores sociais convidados para participar do Conexões Urbanas na estruturação da orientação argumentativa do programa, consideramos os levantamentos feitos por Bentes et al. (2015), que resultaram na totalização de 7 temáticas para todos os 111 episódios do programa entre o período de 2008 e 2015, quais sejam: Projetos/ONGs (30\%), Questões sociais (18\%), Indivíduos (15\%), Instituições de segurança pública (14\%), Grupos sociais (13\%), Lugares de tensão social $(7 \%)$, Outras instituições (3\%). Conforme as autoras, esse programa pode ser considerado como uma novidade na grade do jornalismo televisivo, especialmente por sua determinação em tematizar, de forma sistemática e organizada, "as transformações sociais bemsucedidas no Brasil e no mundo" (SALLES; FAUSTINI, 2008) promovidas por determinados atores e/ou ações sociais.

A nosso ver, ao privilegiar temáticas polêmicas, que geram discussão na sociedade, tais como a legalização das drogas, a pedofilia, o racismo, a pirataria etc., o Conexões Urbanas se distancia de tradicionais programas de reportagens, que parecem pressupor um tipo de auditório menos afeito a consumir produtos simbólicos diferentes daqueles produzidos pelo main stream. Um estudo que comprova essa última afirmação é o de Boberg (2008), que conclui que o grande programa de reportagem televisivo nacional, o Globo Repórter, tematiza fatos que não envolvem disputa, que não dividem e que formam consenso. Esse estudo vai na mesma direção do de Bourdieu (1997, p.28), que afirma que uma parte da ação simbólica da televisão consiste em atrair a atenção para fatos dos quais se pode dizer que são omnibus, isto é, destinados a todo mundo.

No programa Conexões Urbanas, observa-se que o princípio de tratar de temas omnibus é quebrado na medida em que, nos levantamentos feitos, muitas das temáticas não são consensuais e nem socialmente legitimadas, como é o caso da lei de anistia, da legalização das drogas e das vantagens da pirataria, por exemplo.

Ainda em relação às temáticas do Conexões Urbanas, Bentes et al. (2015) observaram o afastamento desse programa em relação a outras produções jornalísticas televisivas ao verificarem que ele, ao ter privilegiado em suas duas primeiras temporadas a temática "Projetos/ONGs", construiu sua identidade como a de um programa jornalístico televisivo que se mostra tanto mobilizador da sociedade na defesa de ações sociais que minimizem a desigualdade social como também incentivador de atitudes de empreendedorismo por parte dos indivíduos. Assim, segundo as autoras, o Conexões Urbanas tematicamente se afasta de programas de reportagens oficializados, que se caracterizam por uma seleção de conteúdos pautada principalmente pela busca de temáticas de natureza "sensacional" e/ou "espetacular" (BOURDIEU, 1997).

\subsection{Os atores sociais no Conexões Urbanas}

Para analisarmos as relações entre os tipos de atores sociais e os tipos de argumentos mobilizados por eles em suas falas, empreendemos ainda um levantamento dos atores sociais que são entrevistados no Conexões Urbanas. Os episódios selecionados para esse levantamento fazem parte das três primeiras temporadas, exibidas de 2008 a 2010, e da sétima e última temporada, exibida no final de 2014 e começo de 2015. No total, levantamos a participação dos atores sociais em 65 episódios. A classificação postulada considera a categorização dos participantes nas legendas e também os conteúdos de suas falas. Posteriormente, contabilizamos todos os atores sociais das temporadas analisadas (547 no total) e os distribuímos em categorias elaboradas a partir de suas atividades profissionais e/ou de sua inserção social, conforme pode ser observado no gráfico a seguir. 
Gráfico 1: Atores sociais distribuídos por categoria no programa Conexões Urbanas

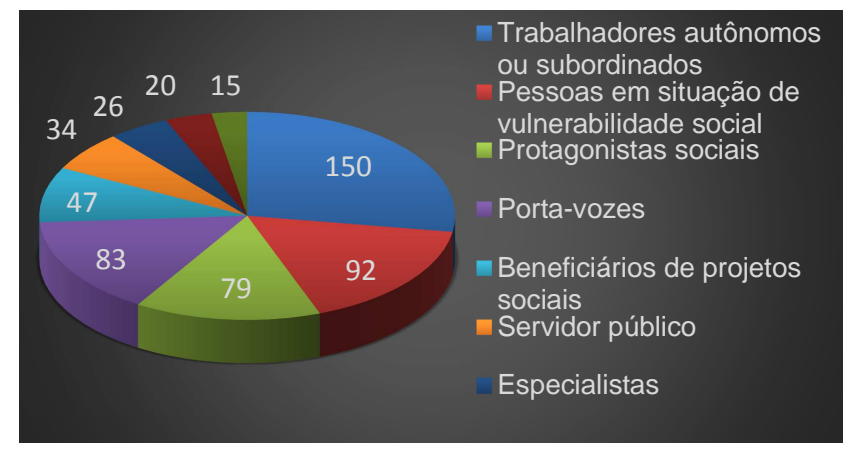

No primeiro episódio selecionado para análise - Circo Social, que integra a temáticas "Projetos sociais/ONGs", - os convidados são: dois protagonistas sociais, um trabalhador subordinado, um beneficiário de projeto social e ainda um portavoz. Já no segundo episódio selecionado - Anistia, que integra a temática "Questões sociais", - há a participação de especialistas, porta-vozes, protagonistas sociais e de pessoas em situação de vulnerabilidade social. Sendo assim, os episódios selecionados contemplam a quase totalidade dos atores sociais que participam do programa Conexões Urbanas.

\section{A argumentação no programa Conexões Urbanas}

\subsection{Tipos de argumentos e estratégias argumentativas}

Apesar de o programa Conexões Urbanas não ser representativo de um gênero prototipicamente argumentativo, como um debate, ele apresenta teses que são enunciadas em cada um dos seus episódios e que são corroboradas por argumentos, construídos pelos participantes. Assim, cada episódio, considerado aqui como um texto organizado, busca obter a adesão de seu auditório por meio do discurso construído conjuntamente por diferentes atores sociais com diferentes inserções no mundo social, desempenhando diferentes atividades.

Para desenvolvermos nossas análises, baseamo-nos principalmente nos estudos de
Perelman \& Olbrecht-Tyteca ([1996]2005), que estabelecem diversos esquemas de argumentos cuja função é sistematizar as possíveis estratégias utilizadas nas interações, reconhecendo que o emprego dessas estratégias vincula-se à finalidade de agir sobre o outro. Considerando os dois procedimentos fundamentais nos processos argumentativos - a ligação e a dissociação de noções, esses autores propõem a seguinte tipologia de argumentos: (i) argumentos quase-lógicos; (ii) argumentos baseados na estrutura do real; e (iii) argumentos que fundam a estrutura do real.

Os argumentos quase-lógicos têm sua força argumentativa relacionada com a sua semelhança em relação aos raciocínios do tipo lógico. Entre esses tipos de argumentos estão, segundo os autores, aqueles que apelam para estruturas lógicas (como os argumentos de contradição, identidade ou definição, transitividade, reciprocidade, comparação e sacrifício) ou aqueles que apelam para relações matemáticas (como os argumentos de inclusão da parte no todo ou de divisão do todo em partes e os argumentos de probabilidade).

Os argumentos fundados na estrutura do real valem-se dessa estrutura para "estabelecer uma solidariedade entre juízos admitidos e outros que se procura promover" (PERELMAN \& OLBRECHTSTYTECA, [1996] 2005, p. 297). Sua força, então, reside na característica de partirem de coisas reconhecidas para introduzir outras que se querem ver admitidas. São argumentos desse tipo: de ligação causal, pragmático, de desperdício, de direção, de superação, de interação entre ato e pessoa, de autoridade, de ato e essência, de relação simbólica, de dupla hierarquia, de grau e ordem.

Por fim, a força dos argumentos que fundam a estrutura do real reside essencialmente na sua capacidade de proceder a generalizações, procurando estabelecer regras e princípios. Estão incluídos nessa categoria os argumentos por exemplo, por ilustração, por modelo e por analogia.

Segundo Perelman \& Olbrechts-Tyteca ([1996]2005), os tipos de acordo suscetíveis ao objeto de crença ou adesão desempenham um papel 
diferente no processo argumentativo e pertencem a duas categorias: uma relativa ao real - que comportaria fatos, verdades e presunções - e outra ao preferível - que conteria valores, hierarquias e lugares do preferível. Ainda segundo os autores, "tudo o que se presume versar sobre o real se caracteriza por uma pretensão de validade para o auditório universal" e, em contrapartida, aquilo que versa sobre o preferível "será ligado a um ponto de vista determinado que só podemos identificar com o de um auditório particular, por mais amplo que seja" (p. 74).

\subsection{A argumentação no episódio Circo Social}

Ao apresentar a trajetória de vida dos idealizadores e dos beneficiários do projeto social "Crescer e Viver", sediado na Praça Onze, no Rio de Janeiro, que atende cerca de 300 crianças e jovens, o episódio Circo Social, exibido em 06/11/2009, defende o poder do circo em transformar social e economicamente as trajetórias de vida de sujeitos oriundos da periferia. Essa tese se sustenta, por um lado, nos argumentos de que os projetos sociais que envolvam o circo possibilitam a saída dos jovens da situação de vulnerabilidade social em que se encontram; e, por outro lado, nos argumentos de que trabalhar em projetos de circo social possibilita ao artista um acúmulo de capital simbólico, principal vetor de transformação social em sua vida.

Conforme podemos observar na tabela 1, a seguir, a argumentação nesse episódio é feita principalmente por meio de relatos, ou seja, argumentos de ilustração, no caso das falas do beneficiário do projeto social e do trabalhador; e por meio de argumentos pragmáticos, no caso das falas dos protagonistas sociais e do porta-voz.
Tabela 1: Participantes do episódio Circo Social

\begin{tabular}{|c|c|c|c|}
\hline Categoria & Legenda & $\begin{array}{c}\text { Tipo de } \\
\text { argumento } \\
\text { mobilizado }\end{array}$ & $\begin{array}{l}\text { Tipos de } \\
\text { acordo }\end{array}$ \\
\hline \multirow[b]{2}{*}{$\begin{array}{l}\text { Protagonista } \\
\text { social }\end{array}$} & $\begin{array}{l}\text { JP - Fundador e } \\
\text { coordenador } \\
\text { executivo do } \\
\text { "Crescer e Viver" }\end{array}$ & \multirow{2}{*}{\begin{tabular}{|c|} 
1) \\
Argumento \\
quase- \\
lógico: \\
definição \\
normativa \\
2) \\
Argumentos \\
baseados \\
na estrutura \\
do real: \\
pragmáticos
\end{tabular}} & \multirow{2}{*}{$\begin{array}{l}\text { Relativos } \\
\text { ao } \\
\text { preferível } \\
\text { (valores, } \\
\text { hierarquia) }\end{array}$} \\
\hline & $\begin{array}{l}\text { VD - Palhaço e } \\
\text { coordenador } \\
\text { executivo do } \\
\text { "Crescer e Viver" }\end{array}$ & & \\
\hline $\begin{array}{c}\text { Beneficiário } \\
\text { de projeto } \\
\text { social }\end{array}$ & $\begin{array}{l}\text { DM - Aluno (do } \\
\text { Projeto "Crescer } \\
\text { e Viver") }\end{array}$ & $\begin{array}{c}1 \text { 1) } \\
\text { Argumento } \\
\text { que funda a } \\
\text { estrutura do } \\
\text { real: } \\
\text { ilustração } \\
\text { por } \\
\text { testemunho }\end{array}$ & $\begin{array}{l}\text { Relativo } \\
\text { ao real }\end{array}$ \\
\hline Trabalhador & $\begin{array}{l}\text { RS - Acrobata } \\
\text { (do Projeto } \\
\text { "Crescer e } \\
\text { Viver") }\end{array}$ & $\begin{array}{c}\text { 1) } \\
\text { Argumento } \\
\text { que funda a } \\
\text { estrutura do } \\
\text { real: } \\
\text { ilustração } \\
\text { por } \\
\text { testemunho } \\
\text { 2) } \\
\text { Argumento } \\
\text { baseado na } \\
\text { estrutura do } \\
\text { real: } \\
\text { pragmático }\end{array}$ & $\begin{array}{l}\text { Relativo } \\
\text { ao real/ } \\
\text { Relativo } \\
\text { ao } \\
\text { preferível } \\
\text { (valores, } \\
\text { hierarquia) }\end{array}$ \\
\hline Porta-voz & $\begin{array}{l}\text { LN - Gerente de } \\
\text { responsabilidade } \\
\text { social da } \\
\text { Petrobrás }\end{array}$ & $\begin{array}{c}1 \text { 1) } \\
\text { Argumento } \\
\text { baseado na } \\
\text { estrutura do } \\
\text { real: vínculo } \\
\text { causal }\end{array}$ & $\begin{array}{l}\text { Relativo } \\
\text { ao } \\
\text { preferível } \\
\text { (valores) }\end{array}$ \\
\hline
\end{tabular}

Tendo em vista os tipos de acordo postulados por Perelman \& Olbrechts-Tyteca ([1996]2005), é possível estabelecer a seguinte correlação: os atores sociais que apresentam argumentos mobilizando acordos relacionados ao real são o trabalhador e o beneficiário do projeto, atores esses que podem ser considerados como apresentando um status social mais baixo do que os outros dois atores sociais (o protagonista social e o porta-voz). A seguir, veremos com mais detalhes o modo de estruturação da argumentação de cada um dos atores sociais que participam do programa. 


\subsubsection{Estratégias argumentativas na fala dos protagonistas sociais}

$\mathrm{Na}$ fala dos protagonistas sociais VD e JP, observamos o discurso sobre os impactos positivos do circo social na vida dos moradores das comunidades próximas à instalação do projeto que coordenam. Por meio da referência a esses impactos positivos, esses atores sociais reforçam a tese sobre o funcionamento dos projetos ligados ao circo como vetor de transformação social. A seguir, apresentamos uma das falas de VD sobre alguns desses impactos do projeto:

(1) VD: é:: no passado...e aqui onde:.....acontecia tráfico de drogas aqui...aqui nesse mesmo espaço (...) nesse espaço onde a lona (es)tá...tem uma possibilidade muito:....grande...nos morros então...onde funcionava os esticas...dos morros aqui de São Ca::rlos e do Estácio e tal...a prostituição infantil onde tinha um índice assim...altíssimo assim...e infantil mesmo assim crianças e tal...então...o impacto que tem...de você vir instalá(r) uma lona de CIRco que te remete a PALHAÇO.... show...à música...à dança...à arte à cultura...isso já cria um impacto...sem você fazê(r) nada...sem você dá(r) uma ideia dos caras...isso só de ((barulho com a boca)) instalá(r) uma lona de circo...a galera "pô...tem uma lona ali"-

Nessa fala, VD mobiliza um argumento que pode ser classificado como pragmático, já que há a avaliação de "um ato ou um acontecimento consoante suas consequências favoráveis ou desfavoráveis" (PERELMAN \& OLBRECHTS-TYTECA, [1996] 2005, p.303). Isso porque esse ator avalia positivamente as consequências da instalação do projeto que coordena, tendo em vista que o índice de tráfico de drogas e de prostituição infantil diminuiu após a chegada do "Crescer e Viver" na região. Assim, ficam claros os valores que são colocados em cena, já que o desenvolvimento desse argumento pragmático depende do "acordo sobre o valor das consequências", de forma que o lugar do preferível na fala de VD é construído como sendo a arte e a cultura em detrimento do tráfico e da prostituição, o que valoriza as ações do projeto idealizado por ele e por JP.

Sobre a função social do circo e o seu valor simbólico, o protagonista JP argumenta, na primeira parte do episódio:

(2) JP: hoje a cultura...cada vez (es)tá sendo apropriada...como o vetor de desenvolvimento (...) e quando a gente (es)tá falando de desenvolvimento de crianças e jovens...sobretudo de jovens...na condição do Rio de Jane(i)ro...que você tem...dezoito vírgula dois por cento da juventude...sem estudá(r)...sem trabalhá(r)...sem nenhum tipo de ocupação...sem fazê(r) nada...qué(r) dizê(r)...há que pensá(r) estratégias de inclusão produtiva...e isso é pelo viés do trabalho...é pelo viés da economia... então assim...mais do que ser...uma referência do ponto de vista do circo social...a gente quer sê(r) uma referência da produção circense no Brasil...a gente (es)tá com uns espetáculos...é disputando uma ressignificação estética da produção criativa no circo...o circo como arte...como expressão artística...como modo de organização do espetáculo...ele ele ele vive...aí alguns anos de dificuldade... pela falta de investimento...e também...por uma incapacidade dos gestores nessa área...de pensá(r) uma nova estética pro circo brasile(i)ro...eu acho que o circo brasile(i)ro tem que sê(r) um espaço... criativo...da expressão viva da simbologia...e da diversidade cultural brasile(i)ra

Consideramos que, nessa fala de JP, há a mobilização de duas estratégias argumentativas distintas. A primeira, que se inicia em "hoje a cultura..." e finaliza em "é pelo viés da economia", constitui um argumento pragmático, pois, assim como VD, JP avalia a melhora no desenvolvimento de crianças e jovens após a implantação do projeto "Crescer e Viver" na comunidade. JP ressalta em sua fala o fato de que o projeto buscou dar um trabalho para parte dos $18,2 \%$ de jovens que não possuíam ocupação.

Em seguida, no trecho que vai de "então assim...mais do que ser...uma referência" até o final de sua fala, JP mobiliza a argumentação por definição. Nesse tipo de argumento, classificado por Perelman \& Olbrechts-Tyteca ([1996] 2005) como quase-lógico, há a identificação não-arbitrária ou não 
evidente de diversos elementos que são o objeto de discurso. Assim, essa identificação é quase-lógica por circunstanciar uma justificação argumentativa. No caso da definição construída por JP, podemos classificá-la como normativa, pois esse ator social indica a forma como quer que o "circo" seja definido: além de colocar seu projeto de circo social como uma referência para a produção circense no Brasil, JP defende que o circo deve ser pensado por todos como expressão artística e como um espaço de criatividade, de simbologia e de diversidade cultural brasileira.

Além disso, esse protagonista social deixa claro que, mais do que a inclusão produtiva, é necessário que haja a valorização estética do circo. Sendo assim, JP coloca o capital simbólico construído como mais importante hierarquicamente do que o capital econômico, representado pela inclusão produtiva. Desse modo, assim como o protagonista social VD, JP também estabelece um tipo de acordo relativo ao preferível na medida em que constrói, por meio da sua argumentação, hierarquia de valores referentes ao circo.

\subsubsection{Estratégias argumentativas na fala do porta-voz}

Consideramos que na fala de LN - ator social categorizado como porta-voz da Petrobras, há a construção do argumento de vínculo causal, conforme podemos observar a seguir:

(3) LN: desde dois mil e sete...é um apoio que vai desde o recurso...pra o desenvolvimento de atividades...é:.....socioculturais e educacionais...com cerca de cento e cinquenta crianças e jovens...envolvidos no projeto...e também o apoio para...a produção...dos espetáculos...inclusive... gerando condição...pra que a gente tenha parte dos ingressos...a/do oferecidos ao público... gratuitamente...e outra parte que é dividida...porque são preços populares...mas que geram uma receita...dividida...parte pra própria: instituição...pra que ele possa reaplicá(r)...em suas atividades... trinta por cento...dessa outra metade...e os outros setenta por cento...distribuídos pros próprios jovens...que participam dessas atividades né?

Segundo Perelman \& Olbrechts-Tyteca ([1996] 2005), um dos tipos de argumentação de vínculo causal é aquela em que, dado um acontecimento, são evidenciados os efeitos que dele devem resultar. No caso de LN, isso fica evidenciado na medida em que ele aproxima dois elementos por meio de uma relação causal: os recursos disponibilizados pela empresa em que atua permitem a produção dos espetáculos do "Crescer e Viver" e o oferecimento de ingressos a preços populares ao público, democratizando o acesso a um bem cultural como o circo, que, segundo LN, pode ser utilizado como uma ferramenta de transformação social tanto para quem participa de sua produção quanto para aqueles que o consideram uma atividade cultural.

\subsubsection{Estratégias argumentativas na fala do beneficiário de projeto social e do trabalhador subordinado}

Motivados pelas perguntas do apresentador, o beneficiário do projeto "Crescer e Viver", DM, e o funcionário desse projeto, RS, apresentam argumentos de ilustração por testemunho, de forma a defenderem a tese de que o circo é um vetor de transformação social da vida de seus artistas, conforme podemos ver a seguir:

(4) DM: a melhor coisa que tem...é a volta por cima (...) entendeu?...é a volta por cima...tem males...tem coisa que a gente escuta...a gente num tem que debatê(r)...a gente tem que guardá(r)...e mostrá(r) em cena...entendeu?...o que eu posso fazê(r) eu estou aqui fazen(d)o...como acontece comigo..."(vo)cê trabalha?"-...-"trabalho"-...-"trabalha em quê?"-...-"em Circo"-...-"que que você faz?"-... "trapézio"- ... -"QUÊ?...(vo)cê faz trapézio tudo?"((risos)) -"ah não...vai arrebentá(r) a cortina...não sei quê ((risos))"- então...então ((risos)) de vez em quando...tem algumas coisas (inint) a pessoa já foca...aquele...sabe?...aquele não não aquele eu não acredito...aí tu pega o DVD...aí mostra...-"é montagem...é montagem"- ((risos))

(5) RS: em:: oitenta e dois...aí o que aconteceu?...ele me indicô(u) pra:: dá(r) um pulo aqui no:: no Circo 
Tihany...pra conversá(r) com eles...e alguém do Circo Tihany...conhecia o diretor da Escola Nacional de Circo na praça da Bandê(i)ra...aí me indicô(u) pra Escola Nacional de Circo...aí daí...depois de quatro anos eu me formei na Escola de Circo...aí (inint.) me pegô(u) pra trabalhá(r) com eles...eu fui pro:: Festival de Circo do Amanhã...na em Paris...aí de lá uma:: uma olhê(i)ra do Circo de Soleil...uma pessoa que (es)tava procurando talentos...me viu e aí me chamô(u) pra ir pro Circo Soleil

O argumento de ilustração por testemunho, segundo Perelman \& Olbrechts-Tyteca ([1996] 2005, p. 407), "reforça a adesão a uma regra conhecida e aceita, fornecendo regras particulares que esclarecem o enunciado geral", de forma a "impressionar vivamente a imaginação". Além disso, a ilustração é capaz de criar a "tendência de nela ver uma imagem", pois causa uma repercussão afetiva (p. 410), funcionando como uma estratégia que visa a fortalecer o tema debatido na medida em que apresenta exemplos que exigem detalhes concretos.

Com base em Oléron (1983, p.91), podemos dizer que os recursos utilizados por DM e RS são capazes de provocar emoção e de mobilizar cargas afetivas, gerando empatia em seu auditório, na medida em que seus discursos apresentam fatos reais de suas vidas que são marcados por momentos de superação de desafios.

Ainda podemos dizer que o relato de RS contribui para ilustrar que o trabalho no circo possui o mesmo estatuto que qualquer outro tipo de trabalho artístico na medida em que permite seu crescimento profissional e econômico. O beneficiário DM, por sua vez, sustenta seu argumento por meio de um testemunho de superação, estratégia esta que tem um alcance emocional considerável em seu auditório, segundo Oléron (1983). Assim, ao trazer o discurso direto de pessoas que duvidavam de sua capacidade como artista de circo e ao destacar a atividade que desenvolve nos espetáculos, DM pode promover nos telespectadores a adesão ao discurso de que o circo é importante do ponto de vista social e simbólico, reforçando a ideia de que ele promove uma transformação na vida dos indivíduos que dele participam.

\subsection{A argumentação no episódio Anistia}

No episódio Anistia, exibido em 20/10/2010, a tese defendida é a de que deva existir uma lei de anistia para criminosos (condenados ou não), que se configura como uma alternativa à privação da liberdade para quem cometeu algum crime. Essa tese é bastante polêmica e envolve o conceito de "perdão judicial". Na tabela 2, a seguir, apresentamos o tipo de argumento que os participantes do programa mobilizam para corroborar essa tese e o tipo de acordo que estabelecem com o auditório:

Tabela 2: Participantes do episódio Anistia

\begin{tabular}{|c|c|c|c|}
\hline $\begin{array}{l}\text { Categ } \\
\text { oria }\end{array}$ & Legenda & $\begin{array}{l}\text { Tipo de argumento } \\
\text { mobilizado }\end{array}$ & $\begin{array}{l}\text { Tipos de } \\
\text { acordo }\end{array}$ \\
\hline $\begin{array}{l}\text { Apres } \\
\text { entad } \\
\text { or }\end{array}$ & - & $\begin{array}{l}\text { 1) Argumento quase- } \\
\text { lógico: definição } \\
\text { 2) Argumento que funda } \\
\text { a estrutura do real: } \\
\text { ilustração }\end{array}$ & $\begin{array}{c}\text { Relativo ao } \\
\text { real }\end{array}$ \\
\hline \multirow{5}{*}{$\begin{array}{l}\text { Pesso } \\
\text { a em } \\
\text { situaç } \\
\text { ão de } \\
\text { vulner } \\
\text { abilida } \\
\text { de } \\
\text { social }\end{array}$} & $\begin{array}{c}\text { CG - } \\
\text { Detento e } \\
\text { Supervisor } \\
\text { de Campo } \\
\text { do Projeto } \\
\text { Empregabili } \\
\text { dade }\end{array}$ & $\begin{array}{l}\text { 1) Argumento baseado na } \\
\text { estrutura do real: ligação } \\
\text { causal } \\
\text { 2) Argumento que funda } \\
\text { a estrutura do real: } \\
\text { ilustração } \\
\text { 3) Argumento baseado na } \\
\text { estrutura do real: } \\
\text { pragmático }\end{array}$ & \multirow{5}{*}{$\begin{array}{l}\text { Relativo ao } \\
\text { preferível } \\
\text { (valores, } \\
\text { hierarquias } \\
\text { e lugar do } \\
\text { preferível) }\end{array}$} \\
\hline & $\begin{array}{c}\text { EP - } \\
\text { Traficante }\end{array}$ & $\begin{array}{l}\text { 1) Argumento que funda } \\
\text { a estrutura do real: } \\
\text { ilustração }\end{array}$ & \\
\hline & $\begin{array}{l}\text { NB - } \\
\text { Foragido da } \\
\text { Justiça }\end{array}$ & $\begin{array}{l}\text { 1) Argumento que funda } \\
\text { a estrutura do real: } \\
\text { ilustração }\end{array}$ & \\
\hline & $\begin{array}{c}\text { MS- Detento } \\
\text { Bangu } 1\end{array}$ & $\begin{array}{l}\text { 1) Argumento que funda } \\
\text { a estrutura do real: } \\
\text { ilustração } \\
\text { 2) Argumento baseado na } \\
\text { estrutura do real: de } \\
\text { autoridade } \\
\text { 3) Argumento que funda } \\
\text { a estrutura do real: } \\
\text { modelo }\end{array}$ & \\
\hline & $\begin{array}{c}\text { MT - } \\
\text { Detento } \\
\text { Bangu } 3\end{array}$ & $\begin{array}{l}\text { 1) Argumento que funda } \\
\text { a estrutura do real: } \\
\text { ilustração }\end{array}$ & \\
\hline
\end{tabular}




\begin{tabular}{|c|c|c|c|}
\hline $\begin{array}{l}\text { Protag } \\
\text { onista } \\
\text { Social }\end{array}$ & $\begin{array}{l}\text { NG - } \\
\text { Coordenado } \\
\text { r do Proj. } \\
\text { Empregabili } \\
\text { dade }\end{array}$ & $\begin{array}{l}\text { 1) Argumento que funda } \\
\text { a estrutura do real: } \\
\text { ilustração }\end{array}$ & $\begin{array}{l}\text { Relativo ao } \\
\text { real }\end{array}$ \\
\hline \multirow{2}{*}{$\begin{array}{c}\text { Porta- } \\
\text { voz }\end{array}$} & $\begin{array}{l}\text { MF - } \\
\text { Deputado } \\
\text { Estadual }\end{array}$ & $\begin{array}{l}\text { 1) Argumento quase- } \\
\text { lógico: comparação } \\
\text { 2) Argumento baseado na } \\
\text { estrutura do real: } \\
\text { pragmático }\end{array}$ & \multirow{2}{*}{$\begin{array}{l}\text { Relativo ao } \\
\text { preferível } \\
\text { (valores, } \\
\text { hierarquias } \\
\text { e lugar do } \\
\text { preferível) }\end{array}$} \\
\hline & $\begin{array}{c}\text { CC - } \\
\text { Secretário } \\
\text { de Adm. } \\
\text { Penitenciári } \\
\text { a } \\
\end{array}$ & $\begin{array}{l}\text { 1) Argumento quase- } \\
\text { lógico: argumento pelo } \\
\text { sacrifício }\end{array}$ & \\
\hline $\begin{array}{l}\text { Especi } \\
\text { alista } \\
\text { (em } \\
\text { Planej } \\
\text { ament } \\
0 \\
\text { Urban } \\
\text { o) }\end{array}$ & $\begin{array}{c}\text { MO - } \\
\text { Pesquisador } \\
\text { a }\end{array}$ & $\begin{array}{l}\text { 1) Argumento que funda } \\
\text { a estrutura do real: } \\
\text { modelo }\end{array}$ & $\begin{array}{l}\text { Relativo ao } \\
\text { preferível } \\
\text { (lugar do } \\
\text { preferível) }\end{array}$ \\
\hline $\begin{array}{l}\text { Especi } \\
\text { alista } \\
\text { (em } \\
\text { Direito } \\
\text { Penal) }\end{array}$ & $\begin{array}{c}\text { TS - } \\
\text { Advogado }\end{array}$ & $\begin{array}{l}\text { 1) Argumento baseado na } \\
\text { estrutura do real: de } \\
\text { autoridade }\end{array}$ & $\begin{array}{c}\text { Relativo ao } \\
\text { real }\end{array}$ \\
\hline
\end{tabular}

De forma geral, foi possível observar que os participantes classificados como "pessoa em situação de vulnerabilidade social" e como "protagonista social" desenvolvem, principalmente, argumentos por ilustração, apresentando seus casos como ilustração para sustentar a tese sobre a necessidade de uma lei de anistia.

$\mathrm{Na}$ fala dos outros atores sociais que participam do episódio, observamos uma maior diversidade dos tipos de argumentos mobilizados: argumentos quase-lógicos, argumentos baseados na estrutura do real e argumentos que fundam a estrutura do real.

\subsubsection{Estratégias argumentativas na fala do apresentador}

O apresentador inicia o episódio expondo a definição de anistia:

(6) JJ: anistia vem do grego anistia que significa esquecimento...fora do dicionário...é o ato pelo qual o poder público...percebe a utilidade social de perdoar um crime...ou o delito de alguém (...)
Segundo Perelman \& Olbrechts-Tyteca ([1996] 2005), a definição constitui uma figura de caracterização que cria um quadro de referência para que se avalie o que está em discussão. Na expressão referencial destacada, podemos observar que JJ já começa a orientar argumentativamente o episódio em favor da anistia, na medida em que esta ação é categorizada como uma "utilidade social", ou seja, é uma ação que traz benefícios à sociedade. Nesse sentido, essa definição é estratégica, pois coloca em jogo o ponto de vista a partir do qual o programa pretende tematizar a anistia. JJ também é o responsável por enunciar a tese do episódio:

(7) JJ: eu coloquei na minha cabeça que eu quero muito trabalhá(r) um tema...que é tipo com uma lei de anistia né? pra pessoas que nem você...querem largá( $r$ a criminalidade...tenham uma/essa oportunidade de...começá(r) do zero (...)

O apresentador também mobiliza um argumento de ilustração a partir do qual ele sustenta a ideia de que ex-traficantes podem mudar de vida se Ihes forem dadas oportunidades para isso.

\subsubsection{Estratégias argumentativas usadas na}

fala das pessoas em situação de vulnerabilidade social e do protagonista social

Como já dissemos anteriormente, o argumento de ilustração é a principal estratégia mobilizada pelo protagonista social e pelas pessoas em situação de vulnerabilidade social que participam do programa. No caso da fala a seguir, o detento em regime semiaberto expõe seu desejo de "começar de novo":

(8) CG: eu sempre quis mudá(r) minha vida entendeu?...EU e muitos companheiro que tenho amigo meu que...a maior vontade deles cara...é...é...vivê(r) com a vida deles a família e vivê( $r)$ com a família deles na casa deles tranquilo...saí dessa vida de crime...mas não encontra oPÇÃO cara (...)

Assim como CG, outros atores sociais classificados como pessoas em situação de vulnerabilidade social (EP, MT, MS) lançam mão de argumentos por ilustração, fornecendo casos 
particulares que reforçam a adesão à tese de modo a impressionar vivamente a imaginação dos interlocutores sobre a necessidade real de uma lei de anistia.

Podemos dizer ainda que a recorrência da argumentação por ilustração ao longo do episódio funciona como uma estratégia de repetição e de reforço à tese. Perelman \& Olbrechts-Tyteca ([1996] 2005) elencam a repetição como uma figura de presença que tem por função manter presente na memória do interlocutor o que se quer fixar, a adesão que se busca. No caso dos discursos dos participantes do Conexões Urbanas, há a repetição tanto de itens lexicais, como "largar", "mudar", "anistia", "oportunidade", quanto da própria ação de expor o desejo de "mudar de vida", "sair dessa vida de crime", "viver outra vida" etc. No caso dessa estratégia de presença, cabe ressaltar que o próprio programa, por meio do processo de edição, é responsável por reforçá-la, de modo que os discursos dos porta-vozes e dos especialistas são intercalados com os discursos desses atores que estão em situação de vulnerabilidade social.

Também cabe ressaltar que, nessas falas, nas quais são enunciados os argumentos por ilustração, o tipo de acordo estabelecido pelos atores sociais é relativo ao preferível, na medida em que os detentos e foragidos da justiça são construídos como pessoas que merecem oportunidades de reverter sua vulnerabilidade social, quebrando, assim, com o valor social mais aceito, de que criminosos não devem ter suas penas anistiadas.

Assim, o programa, ao ilustrar a existência de indivíduos que conseguiram deixar a criminalidade por meio do projeto "Empregabilidade" ou que querem alguma oportunidade de mudar de vida, busca enfraquecer ideias socialmente aceitas, tais como "bandido bom é bandido morto" ou "bandido bom é bandido condenado e preso"3. Nesse caso, as

\footnotetext{
3 Segundo pesquisa do Datafolha de 2015, encomendada pela ONG Fórum Brasileiro de Segurança Pública, 50\% dos entrevistados concordam com a afirmação "Bandido bom é bandido morto". Fonte: http://www1.folha.uol.com.br/cotidiano/2015/10/1690176metade- do-pais- acha-que-bandido-bom- e-bandido- mortoaponta- pesquisa.shtml. Acesso em 01/09/2016.
}

repetições dos desejos desses atores sociais por meio de diversos recursos linguístico-discursivos colaboram com a ideia da necessidade de ações sociais e institucionais concretas que possibilitem a saída das pessoas da criminalidade. No programa, a mais importante dessas ações é a anistia associada à ressocialização.

\subsubsection{Estratégias argumentativas usadas na fala dos porta-vozes}

$\mathrm{Na}$ fala dos porta-vozes MF e CC, podemos observar a construção de argumentos quase-lógicos. Analisamos aqui o argumento de comparação, construído por MF:

(9) MF: eu (es)tô(u) sendo assaltado...bem aquela pessoa foi presa...resolveu o problema da segurança...o que não é verdade(i)ro...muitas vezes quando essa pessoa é presa...esse problema (es)tá apenas começando.. porque ele vai sê(r) preso...ele vai pra uma unidade da Polinter...ele lá vai tê(r) que sê(r) classificado pela facção que ele pertence mesmo se ele não (es)tivé(r) em nenhuma facção...ele vai ficá(r) um dois três anos em condições absurdas...convivendo...apenas exclusivamente com a violência...sem nenhuma perspectiva...muitas vezes dilacerando a sua família...que já teria problemas e volta pra uma sociedade com uma chance de cometê( $r$ ) novos crimes muito maior(es)...é isso que nós queremos insistí(r) fingí(r) que não (es)tá acontecendo? a proposta da anistia visa pegá(r) ESSA pessoa...que hoje (es)tá...com alguma atitude criminosa...e dá(r) a ele uma alternativa diferente...da privação da liberdade...da tortura...dos maus tratos...do abandono...por um preço mais barato...porque nós oferecemos isso tudo por um preço caro... prisão...é uma mane(i)ra muito cara que torna as pessoas piores...porque se vocês gastava mil e oitocentos reais né? pra essas pessoas ficarem na prisão...você gasta pra eles entrarem pr'um programa de anistia...onde eles serão acompanhados...vão tê(r) acesso ao acompanhamento psicológico social...tê(r) acesso a estudo e a trabalho...e a chance dele...voltá(r) ao crime passa a sê(r) muito menor...a chance dele se reintegrá(r) na sociedade é muito 
melhor...com o dinheiro... que você antes gastava pra torná-la ainda pior

Por meio do argumento de comparação, MF desqualifica a política de privação da liberdade do indivíduo que cometeu algum crime, para, em seguida, justificar, do ponto de vista econômico (em termos de valores gastos) e social (em termos das chances de reintegração à sociedade e de saída da criminalidade), a proposta de um programa de anistia, aliado a um programa que envolva a reinserção social. Isso porque, segundo MF, a anistia proporcionaria maiores chances de reintegração do indivíduo à sociedade e menores chances de ele voltar à criminalidade, na medida em que ofereceria acompanhamento psicológico e acesso a estudo e trabalho, evitando que o preso viva sob a condição de violência. Nesse tipo de argumentação, cotejam-se duas ações para avaliá-las uma em relação à outra de forma que aquela considerada inferior tende a sofrer com a comparação (PERELMAN \& OLBRECHTS-TYTECA, [1996] 2005).

Ainda cabe destacar que, ao construir 0 argumento comprovando que a anistia é mais viável que a prisão, com base em hierarquia e valores, MF opta por defender determinado ponto de vista que vai de encontro a ideias popularmente defendidas como as de que "bandido bom é bandido morto" ou "bandido bom é bandido condenado e preso" - por meio do estabelecimento de valores e hierarquias (anistia > prisão), o que está ligado à atuação social de MF como porta-voz dos grupos e instituições que defendem os direitos humanos. Por isso, apesar de seu argumento versar sobre o preferível, essa estratégia estaria ligada, a nosso ver, a esse papel social de porta-voz de grupos e instituições.

\subsubsection{Estratégias argumentativas usadas na fala dos especialistas}

Na fala do especialista TS, a seguir, podemos observar o uso de duas estratégias importantes no fortalecimento de um auditório universal: a antecipação de objeções de forma a invalidar os contra-argumentos que podem ser mobilizados pelos interlocutores e a mobilização de argumento de autoridade.

(10) TS: a anisti::a que tem um caráter do perDÃO do ESquecimento é um instituto de natureza:: eminentemente...política...então na questão do/da criminalidade coMUM...do homem que se enVOLve no cri::me...da/do desvi::o...no TRÁfico de drogas ou...ou o que seja...é:....é complicado a gente pensar na ideia de esquecer o FAto né?...a sociedade não vai aceiTAR esquecer o fato de traficar...não vai aceitar esquecer o FAto de praticar crimes comuns não vai aceitar...mas eu acho que nós temos saída pra isso...o...o direito penal tem algumas algumas citações que os alemães chamam de PONte de ouro...é uma PONte que você dá pra você saí(r) do crime...é uma desistência voluntária...você indiCIA a prática de um crime no meio do crime você deSISte...a a lei...te oferece um perDÃO judicial...porque ele...praticou um gesto que foi suficiente que foi capaz...de tirá-lo da situação...do crime não é?...ou de minorar ou evitar ou reduZIR de forma significativa as consequências do do seu ato

Em um primeiro momento de sua fala, TS já prevê as objeções que podem ser feitas à tese de uma lei de anistia que proponha o perdão do crime ou o esquecimento da pena. Ao usar essa estratégia, denominada por Perelman \& Olbrechts-Tyteca ([1996] 2005) como prolepse ou antecipação (praesumptio), o locutor evidencia que procura a adesão de um auditório universal na medida em que mostra reconhecer que teses correntes na sociedade como aquelas que apresentamos anteriormente podem ser objeções à tese que procura defender. Desse modo, TS, ao não negar o quanto é "complicado" "aceitar esquecer o FAto de praticar crimes comuns", provavelmente consegue a adesão de um auditório universal. Para conseguir essa adesão, além de reconhecer as objeções à tese defendida, TS mobiliza um argumento de autoridade por meio do qual ele sugere que a anistia pode ser um mecanismo legal, o que superaria a ideia do esquecimento dos crimes praticados. Assim, ao se embasar em mecanismos legais propostos por especialistas alemães, TS 
sustenta que a anistia pode ser legalmente proposta no contexto brasileiro.

A mobilização desse tipo de argumento por TS está ligada, a nosso ver, à função social exercida por esse ator: como advogado especialista em Direito Penal, ele lança mão de um argumento de autoridade cuja fonte é a legislação alemã. Desse modo, não podemos desconsiderar na construção das estratégias argumentativas, como vem sendo feito nos estudos sobre argumentação, o perfil ou a inserção social do locutor.

Além do argumento do especialista em direito penal TS, também selecionamos o argumento construído pela especialista em Planejamento Urbano:

(11) MO: eu acho que a gente vê por exemplo coisas super interessantes no programa...de reinserção né? dos ex-combatentes de Medelin que é:: DISparado o melhor programa de reinserção do MUNdo em termos concei/conceituais (...) a partir do momento que:....a pessoa se desmobiliza...é:: ela ingressa num programa...que chama Programa de reintegração à vida civil...e inicialmente a ideia era que...durante um ano e meio...essa pessoa recebesse...uma ajuda de custo...você tinha programas especiais pra que eles...pudessem né? enfim...no Mínimo...assim...tê(r) o ensino médio...(vo)cê te::m...reintegração no mercado de traba::Iho...(vo)cê tem educa/reintegração escolar...(vo)cê tem apoio...psicossocial que eles chamam...é importante pra esse cara...tê(r) um lugar onde ele possa falá(r) onde ele possa conversá(r) onde ele possa muitas vezes...discutí(r) essa experiência que ele viveu

Cabe ressaltar que essa fala é inserida no programa após a fala do detento MS, que, assim como a especialista, constrói um argumento de modelo, defendendo a política de anistia na Colômbia como um modelo que pode ser viável também no Brasil. Na fala de MS, observamos que o entrevistado recorre à exemplificação do modelo da Colômbia não para fundamentar ou ilustrar uma regra geral, mas para estimular uma ação no Brasil inspirada nesse modelo. $\mathrm{Na}$ fala da pesquisadora $\mathrm{MO}$, observamos o mesmo tipo de estratégia: ao considerar o programa de reinserção de ex-combatentes de Medellín como "o melhor programa de reinserção do MUNdo em termos concei/conceituais", a especialista reforça a ideia de ele poder funcionar como uma política a ser seguida no Brasil.

A pesquisadora ainda descreve de forma pormenorizada as etapas do processo de reintegração civil de forma que o auditório possa entender que não se trata apenas de um "perdão judicial", mas envolve todo um processo de reinserção, tal como foi sugerido também pelo portavoz MF. Nesse caso, a participante evita objeções à tese na medida em que antecipa que não se trata de uma lei que prevê apenas a liberdade de um indivíduo que cometeu crimes.

Apesar de MO lançar mão dessa estratégia de antecipação, podemos dizer que, na sua fala, há o estabelecimento do lugar do preferível, na medida em que o programa de anistia da Colômbia é construído como um modelo, ou seja, como preferível em relação à legislação penal brasileira.

\section{Considerações finais}

As análises que empreendemos, neste artigo, permitem-nos fazer algumas generalizações acerca da correlação entre os tipos de atores sociais que são convidados a participar do programa Conexões Urbanas e os tipos de argumentos mobilizados por eles em suas falas.

Os argumentos do tipo quase-lógico (de definição, de comparação e de sacrifício) são os menos frequentes nos dois episódios analisados e foram enunciados pelos atores sociais com status social mais alto: o próprio apresentador do programa, os dois coordenadores do projeto "Crescer e Viver" (os protagonistas sociais), o deputado estadual MF e o secretário de administração penitenciária do Rio de Janeiro (os porta-vozes).

Já os argumentos que fundam a estrutura do real, especialmente aqueles que são de ilustração por testemunho, foram os mais mobilizados no episódio Anistia e são relativamente relevantes no episódio Circo Social. Nesses dois episódios, os atores sociais 
que enunciam esse tipo de argumento são aqueles que podem ser considerados como apresentando um status social inferior ao dos outros atores sociais participantes do programa, quais sejam: o trabalhador e o beneficiário de projeto social, no caso do Circo Social, e as pessoas em situação de vulnerabilidade social, no caso do Anistia.

No que se refere à relação entre temática e tipos de argumentos, nossas análises mostraram que, no episódio Circo Social, a tese defendida se sustenta principalmente em argumentos que ilustram, por meio dos testemunhos de um beneficiário de projeto social e de um trabalhador, o fato de que projetos sociais que envolvem "circo" possibilitam a saída de jovens da situação de vulnerabilidade social. Nesse sentido, o texto construído nesse episódio molda um auditório mais afeito a consumir produtos simbólicos produzidos pelo main stream. A diferença desse episódio em relação a outros programas de reportagem televisiva consiste principalmente na presença de uma heterogeneidade de vozes sociais, que inclui tanto atores sociais com status mais alto como aqueles com status social inferior.

Quanto ao episódio Anistia, por tratar de uma temática mais polêmica, sustentada na tese da lei de anistia como uma alternativa à privação da liberdade para quem cometeu algum crime, o texto estruturado argumentativamente prevê um auditório que pode ser contextualizado como não partilhando dos mesmos pressupostos do produtor do programa, que se empenha, pessoalmente, em defender a tese da anistia a criminosos que queiram ter uma segunda chance - daí o título de nosso artigo -, e de seus participantes. Esse não compartilhamento de pressupostos pode ser corroborado pelo fato de que uma grande parcela da população brasileira afirma concordar com a tese de que "bandido bom é bandido morto", conforme investigou pesquisa anteriormente mencionada. Assim, ao tratar de temas mais polêmicos, o Conexões Urbanas contribui para a construção de um novo tipo de auditório para programas de reportagem, moldado por novas opiniões e motivações de interesse.

A reflexão final que não poderíamos deixar de fazer no contexto atual é a de que programas como o
Conexões Urbanas, por sua natureza fortemente argumentativa, pela pluralidade de vozes que são convocadas a constituir o programa e pela escolha de determinados temas polêmicos e pouco consensuais, são de acesso mais restrito, já que esse e outros programas não constam da grade de TV aberta. Desse modo, parecem repercutir e resistir no tempo os programas de reportagens cuja ação simbólica consiste em atrair a atenção do auditório para as temáticas omnibus. Quando há um tratamento aprofundado de determinadas temáticas polêmicas por meio de reportagens, a televisão, de modo geral, não possibilita aos telespectadores o acesso ao tipo de reflexão e de estrutura de participação que caracterizou muitos episódios do Conexões Urbanas. Acreditamos que a tentativa de quebra desse paradigma de apresentação de temáticas omnibus levou o programa a ser descontinuado, tendo ficado no ar ao longo de sete anos, por um tempo semanal menor do que o de outros programas de reportagens e por meio de apenas um pouco mais de uma centena de episódios.

\section{Referências}

ACCETTURI, A. C. A. Gêneros midiáticos em foco: analisando a organização textual-discursiva do programa televisivo Conexões Urbanas. 2015a. 18 f. Relatório final de Iniciação Científica (Pibic/CNPq) - Graduação em Letras, Instituto de Estudos da Linguagem, Universidade Estadual de Campinas, Campinas, 2015a.

Gêneros midiáticos e textualidade: 0 caso do programa Conexões Urbanas. 2015b. $61 \mathrm{f}$. Trabalho final de curso de Letras, Instituto de Estudos da Linguagem, Universidade Estadual de Campinas, 2015b.

AQUINO, Z.G.O. Conversação e conflito: um estudo das estratégias discursivas em interações polêmicas. 1997. 367 f. Tese (Doutorado em Linguística), Faculdade de Filosofia, Letras e Ciências Humanas, Universidade de São Paulo, São Paulo, 1997.

; A mídia impressa e argumentação Construção do ethos em artigo de opinião. In: SILVA, A.S. et al. (Org.). Comunicação Cognição e Mídia. Braga: Editora da Universidade Católica de Portugal, 2010, v. II, p. 671-685.

; LOTTI, A.L.F.C. A Argumentação nos Manifestos: Nhengaçu Verde-Amarelo e 
Poesia Pau-Brasil. Revista Todas as Letras, São Paulo, v. 18, n.1, p. 128-140, jan./abr. 2016.

BENTES, I. Bangu sem clichês. O Estado de São Paulo, São Paulo, em 20/08/2010. Disponível em: http://cultura.estadao.com.br/noticias/geral,bangupara-alem-dos-cliches-imp-,597568. Acesso em 02/08/2016.

BENTES, A.C.; MARIANO, R.D.; ACCETTURI, A.C. Temas e estratégias referenciais em Conexão: analisando processos de estabilização e de mudança em um programa televisivo. ReVEL, v. 13, n. 25, p.316-354, ago. 2015.

BOBERG, A.R. Globo Repórter: uma investigação sobre o estilo textual da reportagem televisiva. 2008. 120f. Dissertação (Mestrado em Estudos Linguísticos), Setor de Ciências Humanas, Letras e artes, Universidade Federal do Paraná, Curitiba, 2008.

BOURDIEU, P. Sobre a televisão. Rio de Janeiro: Jorge Zahar, 1997.

CABRAL, A.L.T. Argumentação na língua e argumentação no texto. Intersecções, Jundiaí, v. 18, n.1, p. 26-40, fev. 2016.

CARVALHO, M.M. Discussões on-line: estratégias de argumentação em debates na internet. 2007. 203 f. Dissertação (Mestrado em Filologia e Língua Portuguesa), Faculdade de Filosofia, Letras e Ciências Humanas, Universidade de São Paulo, São Paulo, 2007.

CAVALCANTE, M.M.; MATOS, J.G. Discutindo as marcas avaliativo-argumentativas das recategorizações. Intersecções, Jundiaí, v. 18, n.1, p. 93-111, fev. 2016.

FARNEDA, E.S. O debate televisivo: um estudo das estratégias argumentativas no discurso feminino. 2007. 133 f. Dissertação (Mestrado em Letras Língua Portuguesa), Faculdade de Filosofia, Letras e Ciências Humanas, Universidade de São Paulo, São Paulo, 2007.

$\mathrm{KOCH}$, I.G.V. Argumentação e linguagem. 13.ed. Cortez: 2011 [1987].
KOTSCHO, R. A prática da reportagem. 4. ed. São Paulo: Ática, 2000.

LIMA, Metadiscursividade e persuasão em entrevistas com candidatos à Prefeitura de São Paulo. 2009. 209 f. Tese (Doutorado em Filologia e Língua Portuguesa), Faculdade de Filosofia, Letras e Ciências Humanas, Universidade de São Paulo, São Paulo, 2009.

OLÉRON, P. A argumentação. Tradução: Cascais Franco. Portugal: Europa América,1983.

PALUMBO, R. Referenciação e argumentação: a dinâmica nas orientações argumentativas em debates políticos televisivos. 2007. $193 \mathrm{f}$. Dissertação (Mestrado em Letras), Faculdade de Filosofia, Letras e Ciências Humanas, Universidade de São Paulo, São Paulo, 2007.

Referenciação, metáfora e argumentação no discurso presidencial. 2013. 271 f. Tese (Doutorado em Letras - Língua Portuguesa), Faculdade de Filosofia, Letras e Ciências Humanas, Universidade de São Paulo, São Paulo, 2013.

PERELMAN, C.; OLBRECHTS-TYTECA, L. Tratado da argumentação. A nova retórica. 2.ed. São Paulo: Martins Fontes, 2005.

SALLES, E.; FAUSTINI, M.V. Programa Conexões Urbanas, do AfroReggae, inova a TV. O Globo, Rio de Janeiro, 03/11/2008.

\section{COMO CITAR ESSE ARTIGO}

BENTES, Anna Christina; MARIANO, Rafaela Defendi; ACCETTURI, Ana Cecília Almeida. "Eu quero muito trabalhar um tema": estratégias argumentativas no programa televisivo Conexões Urbanas. Signo, Santa Cruz do Sul, v. 42, n. 73, jan. 2017. ISSN 1982-2014. Disponível em: <https://online.unisc.br/seer/index.php/signo/article/view/8472>. Acesso em:__. doi: http://dx.doi.org/10.17058/signo.v42i73.8472. 